\title{
Karachi tides during the 1945 Makran tsunami
}

\author{
Loyce M. Adams ${ }^{1 *}$, Brian F. Atwater ${ }^{2}$ (D) and Haider Hasan ${ }^{3}$ (])
}

\begin{abstract}
This paper extends and detides a Karachi tide-gauge record as an observational basis for assessing Indian Ocean tsunami risk. The extended marigram encompasses the time of the great 1945 Makran earthquake of early November 28, local time, and of the ensuing tsunami, which continued into November 29. The marigram was published previously as a 9-h excerpt that begins $1 \mathrm{~h}$ after the earthquake. The full marigram presented here covers most of 17 days from November 15 to December 1. Gaps include a tsunami-induced outage that may help explain why the highest water level gauged is $1 \mathrm{~m}$ below the maximum water level reported nearby. The detiding method computes a reference tidal curve that disregards all observations from November 28 and 29. For those 2 days, the reference tide is guided by Admiralty tide tables and, secondarily, by high waters and low waters gauged before and after. As in previous estimates, the detided tsunami crests about $0.5 \mathrm{~m}$ above ambient tide, but now with the possibility that the gauge failed to record a higher wave. Anomalies described for the first time include an early one that likely resulted from a recognized problem with the Karachi tide station, but which might instead represent an earthquake precursor.
\end{abstract}

Keywords: Tsunami, Tide gauge, Makran, Karachi

\section{Background}

Newspaper stories and a tide-gauge record tell of effects, at Karachi Harbour, of the tsunami associated with the great 1945 Makran earthquake (Figs. 1 and 2). As clues to earthquake and tsunami risk, these Karachi observations are important both regionally on shores of the northwest Indian Ocean (Heidarzadeh et al. 2008; Rajendran et al. 2008; Neetu et al. 2011; Heidarzadeh and Satake 2015; Rastgoftar and Soltanpour 2016; Heidarzadeh and Satake 2017) and locally for Pakistan's principal port (Hasan et al. 2017).

The Karachi marigram is one of the two instrumental records of the 1945 tsunami-the other being more distal, in Bombay (Neetu et al. 2011). The Karachi marigram was previously excerpted and detided for a ninehour period beginning $70 \mathrm{~min}$ after the great earthquake (Neetu et al. 2011; Heidarzadeh and Satake 2015). The earthquake originated at 0327 of November 28, India

*Correspondence: Ima3@uw.edu

${ }^{1}$ Department of Applied Mathematics, University of Washington, Seattle, WA, USA

Full list of author information is available at the end of the article
Standard Time (IST) and attained magnitude 8.0-8.2 (Byrne et al. 1992).

The Karachi marigram is here presented and detided in its entirety. The record spans most of the 17 days between November 15 and December 1. Its notable features include an anomaly that begins before the great earthquake, and a gap that may include the time when Karachi oil installations were flooded. The paper develops an unconventional detiding method to isolate the early anomaly and clarify fluctuations that follow.

The paper sets the stage with tsunami accounts from Karachi and Bombay newspapers and a brief description of the Karachi tide station. A scan of the 17-day marigram (Additional file 1: Fig. S1) provides a basis for discussing gaps in this instrumental record and an early anomaly on November 28. The detiding uses official predictions of Karachi tides (Fig. 3) in deriving a reference tidal curve (Fig. 4). A residual curve includes traces of the tsunami (Fig. 5).

The main text and figures are complemented by three appendices and three data tables. The reference curve is derived mathematically in Additional file 2: Appen$\operatorname{dix} \mathrm{A}$, and is compared with alternatives in Additional 


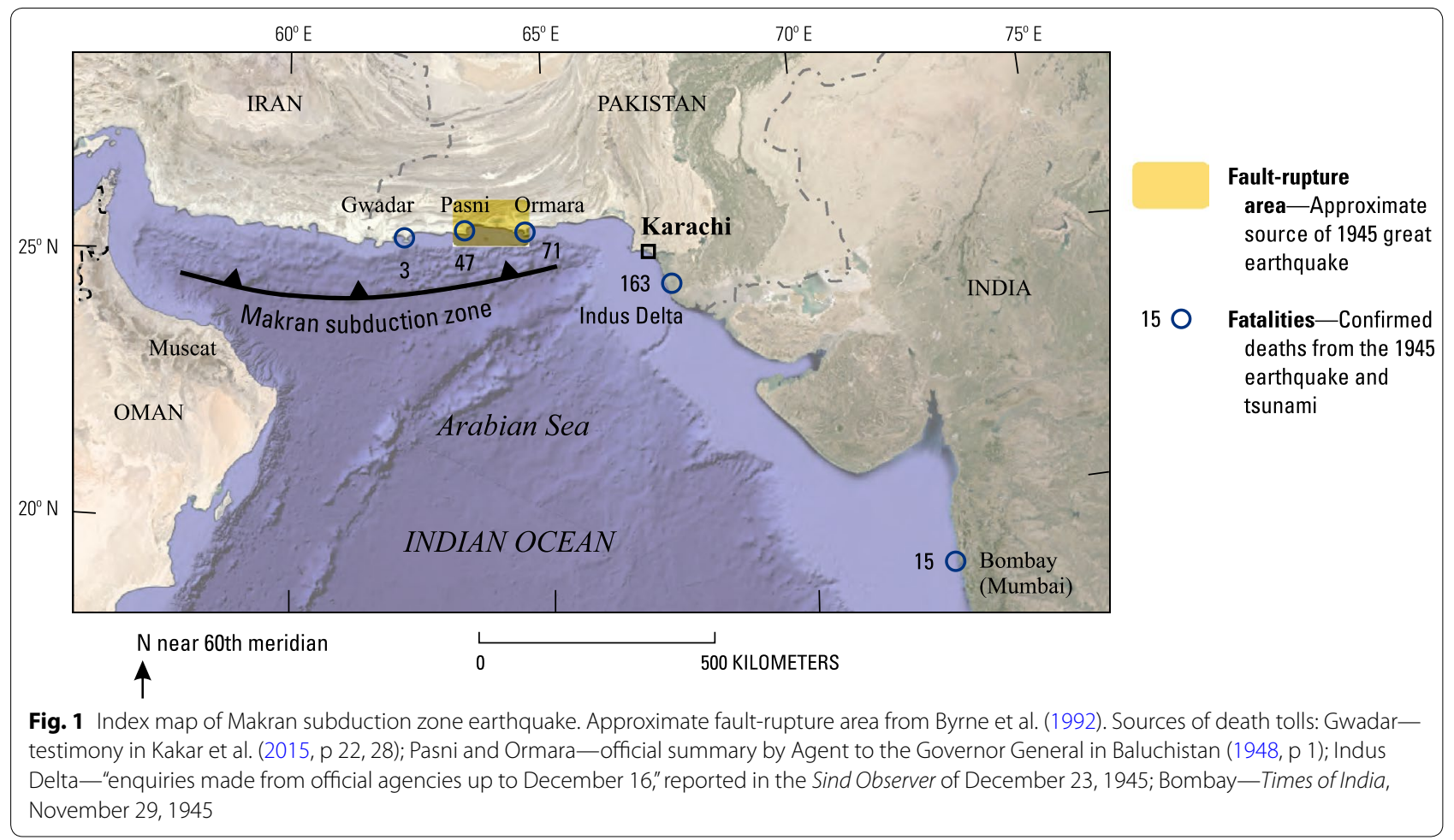

file 2: Appendix B. Whether the early anomaly resulted from instrumental or human error, or from a precursory tsunami, is considered in Additional file 3: Appendix C. The marigram in digital form is presented and detided in Additional file 4: Table S1. Additional file 4 also contains a minute-by-minute version of the reference tide (Table S2) and a list of the high waters and lower waters that were used in computing the reference tide (Table S3).

\section{Verbal observations from Karachi}

The descriptions below draw on sources cited in a recent review (Hoffmann et al. 2013), supplemented by accounts in the November 29 issues of two Karachi dailies-the Daily Gazette and the Sind Observer-in the collection of the Library of Congress, Washington, DC.

\section{Earthquake shaking, tsunami arrivals, and peak water levels}

Shaking from the great Makran earthquake, though weak in Karachi (Ambraseys and Melville 1982), stopped the clock on the Karachi Municipal Clock Tower at 0326 IST on November 28, according to Daily Gazette.

A series of four waves at Karachi was reported in the Times of India of November 30: "The first tidal wave occurred at 5-30 a.m. [0530 IST]. The second, which was bigger, occurred at 7 a.m. There was a third wave at about 7-50 a.m., followed by the biggest at about 8-15 a.m. The after effects of the maximum tidal wave produced a very strong ebbing current of between four and five knots." Water levels peaked close to 0800 IST according to frontpage articles in the Daily Gazette and the Sind Observer. The Observer story further estimates that the "tide," at location not specified, "rose nearly $12 \mathrm{ft}$ high."

Reporters based in Karachi probably filed all these reports. The Gazette and the Observer were the era's leading English-language dailies published in Karachi (Barns 1940, p 427). The Times was published in Bombay, but the byline for its November 30 article reads A.P.I., and the Associated Press of India had a Karachi branch office in 1940 (Sharma 1954, p 6).

\section{Maximum tsunami height relative to ambient tide and with respect to a local datum}

Tsunami heights in these newspaper accounts resemble those in later scientific summaries. Pendse (1946, 1948), after reiterating the four wave times in the Times of India, noted that the reported waves had followed a high tide predicted for 0637 IST. He estimated that the highest water level was " $4 \frac{1}{2} \mathrm{ft}$ above normal." An earthquake catalog states that at Karachi the tsunami reached "a height on land of about 1.5 m" (Ambraseys and Melville 1982, p 90).

The Observer's maximum water level of $12 \mathrm{ft}(3.7 \mathrm{~m})$ is consistent with these detided tsunami maxima of " $4 \frac{1}{2} \mathrm{ft}$ " 


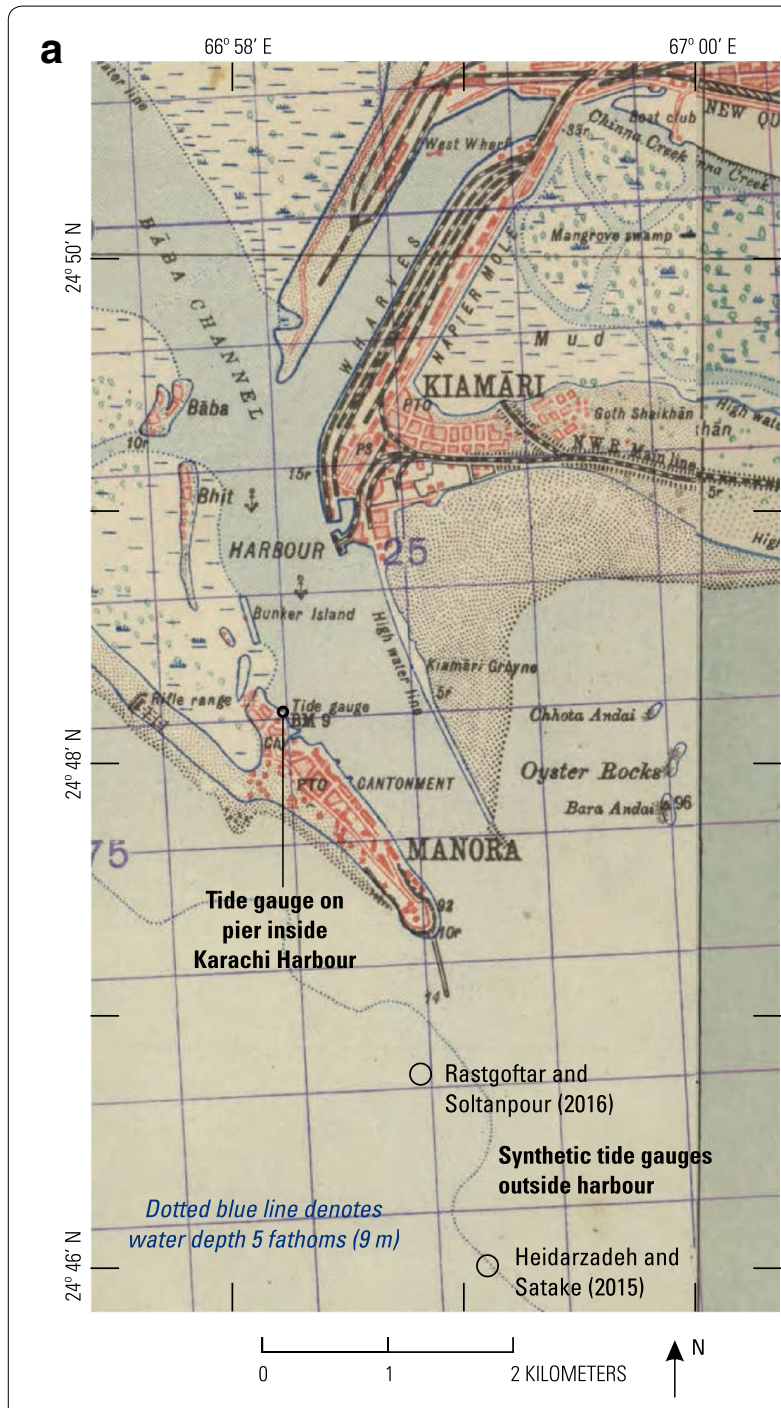

b

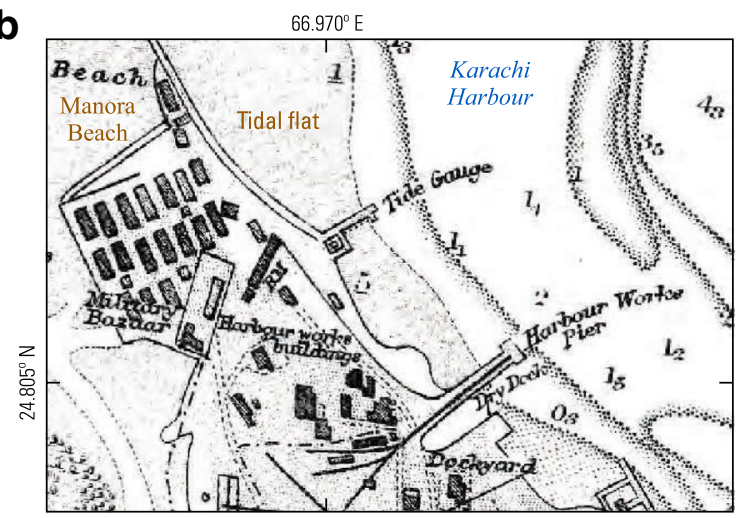

Color labels added

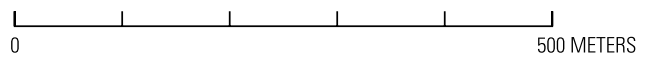

Fig. 2 Location of tidal observatory, on pier at $24.804^{\circ} \mathrm{N}, 66.970^{\circ} \mathrm{E}$ a Karachi Harbour and vicinity, showing locations of synthetic tide gauges used in tsunami modeling: $24.767^{\circ} \mathrm{N}, 66.985^{\circ} \mathrm{E}$ (Heidarzadeh and Satake 2015, p 626); and $24.78^{\circ} \mathrm{N}, 66.98^{\circ} \mathrm{E}$ (Rastgoftar and Soltanpour 2016, p 942). An addition synthetic gauge, at $24.46^{\circ} \mathrm{N}$, $66.80^{\circ} \mathrm{E}$ (Rajendran et al. 2008, p 1742), is outside the map area $40 \mathrm{~km}$ southeast of the pier. Base map from Survey of India One-Inch Sheets 35 L/13, 3rd ed., 1945, and 35 P/1, 4th ed., 1944, both originally surveyed 1925-1926. Military grid in purple. b Detail from Admiralty chart 40, 1939 edition

$(1.4 \mathrm{~m})$ and "about $1.5 \mathrm{~m}$." The 12-ft figure was logically referenced to the datum of the official nautical chart of Karachi Harbour-Admiralty chart 40, editions of which are reviewed in this volume by Hasan et al. (2018). The Admiralty's Karachi tide tables for 1945 predict a high water level of $8.1 \mathrm{ft}$ for 0637 IST (Hydrographic Department 1944, p 106). If the highest wave around 0800 IST, more than an hour after high tide, was superimposed on a tide level of $7 \frac{1}{2} \mathrm{ft}$, the Observer's water level of $12 \mathrm{ft}$ detides to $4 \frac{1}{2} \mathrm{ft}$.

The Observer's maximum water level around $3.7 \mathrm{~m}$ is also consistent with reported flooding. All three newspapers cited above describe flooding of oil installations at Kiamari around 8 o'clock. The oil facilities adjoined tidal flats to the south, from which they were separated by a seawall. The seawall is depicted on the 1944 and 1951 editions of an official topographic map (Karachi Guide Map, scale 1:21,120). In the 1951 edition, which is reproduced as a supplement to Hasan et al. (2018), the seawall height is labeled as $3 \mathrm{ft}(0.9 \mathrm{~m}$; one place) and $4 \mathrm{ft}(1.2 \mathrm{~m}$; in two other places) relative to an adjoining high water line. If this line approximates mean high water springs-a standard tidal datum $2.5 \mathrm{~m}$ above chart datum at Karachi (Hydrographic Department 1944, p 293)-the tsunami overtopped a Kiamari seawall no less than 3.4-3.7 m above chart datum.

These various estimates of maximum water level exceed, by $1 \mathrm{~m}$, the highest water level gauged on November 28 at the Karachi tide station (Fig. 5b). This discrepancy is about twice the maximum detided height of the gauged tsunami, which attains about $0.5 \mathrm{~m}$ above ambient tide irrespective of detiding method (Fig. 5b, c).

\section{Tsunami record from the Karachi tidal observatory}

Mostly new with this paper is a Karachi marigram that extends from November 15 to December 1, 1945. Additional file 1: Figure S1 presents the marigram scan that was provided to us by the Survey of India through the Indian National Centre for Ocean Information Services (INCOIS) 
(See figure on next page.)

Fig. 3 Predicted heights and time intervals for Karachi tides of October-December 1945 (Additional file 2: Additional file 4: Table S3). The tides are grouped into two sets of high tides and two sets of low tides. Successive tides in each set are one lunar day ( $24 \mathrm{~h} 50 \mathrm{~min}$ ) apart on average. a Heights through spring tides (moon new or full) and neap tides (quarter moons). Moon phases from Reingold and Dershowitz (2002, p 92). b Time intervals between successive tides expressed as deviations from one mean lunar day

and the Intergovernmental Oceanographic Commission of UNESCO (UNESCO-IOC). Heights and times obtained from this scan are included in Figs. 3, 4, and 5, and data from a digitized tracing of the marigram are listed in Additional file 4: Table S1. The time intervals between the digitized points range from less than $1 \mathrm{~min}$ to $3 \mathrm{~min}$.

\section{Karachi tide station}

Reliable records of tide levels in Karachi Harbour extend back to 1868 (Hogarth 2014, p 7651). The gauge design, location, and operation were reported in turn-of-the-century monographs of the Great Trigonometrical Survey (Eccles 1901a, b) and operational updates are available through 1945 (for example, Survey of India 1948).

The Karachi gauge in operation in 1945 was situated on a pier where routine tidal observations had begun in 1881 and would continue into 1948 (Fig. 2). The pier's location inside the harbour contrasts with the open-ocean locations of synthetic tide gauges that have been used in tsunami simulations (Fig. 2a). The label "tide gauge" appears beside this pier on the official nautical chart (Admiralty chart 40; Fig. 2b), editions between 1884 and 1955 viewed at the Library of Congress, Washington, DC; on an official topographic map (Karachi Guide Map), editions of 1944 and 1951 (Hasan et al. 2018); and in the smallerscale topographic maps, editions of 1944 and 1945, that are pieced together in Fig. 2a.

The gauge design, if like that of a standard model a half-century earlier (Eccles 1901a, pp 11-13), included a stilling well that communicated with the sea through a hole $2.5 \mathrm{~cm}$ in diameter (Eccles 1901b, p 9). A float in the stilling well was suspended on a perforated copper band that turned a wheel on the graphing device. This wheel, through gears and a cable, moved a pencil across a gridded sheet mounted on a rotating drum nearly $1.6 \mathrm{~m}$ long. The Karachi gauge had been operated to draw tidal fluctuations at 1/3 their actual amplitude (Eccles 1901b, p 9). This same scale is marked at lower right on the marigram for November 15 to December 1, 1945 (Additional file 1: Figure S1).

\section{Marigram description}

This marigram was initially drawn by the tide gauge on a gridded sheet that divides each day into $24 \mathrm{~h}$, and which represents water level in units very close to $0.3 \mathrm{ft}$. The time and height axes are orthogonal to those of conventional graphs (Additional file 3: Fig. C5). The sheet came with lithographed labels that give the time scale in hours; midnight runs lengthwise across the middle of the sheet; and noon is at its top and bottom edges. Lithographed grid lines for water level have been labeled in pencil, and no grid line gives the water-level datum. However, the pencil numbers give high water and low water heights that resemble predictions in the Admiralty tide table, as shown in Additional file 2: Figures B1 and B2, and in Additional file 4: Table S3. Because the tide tables use the datum for soundings on Admiralty chart 40 (the chart datum), we assume that the heights penciled beside the grid lines do as well.

Few traces remain of the tidal curves that had been drawn mechanically while the sheet was on the drum. All the curves appear to have been overwritten in ink. The pencil curves are faint at best, and they are visible mainly where the ink is pale from its color or from water damage, and where the ink deviates from the pencil. The ink color-codes each curve by date. The inking probably began while the sheet was on the drum, as evidenced by circles and dates at 1000 IST and 1700 IST. These marks are consistent with an inspection and inking protocol in use a half-century before (Eccles 1901a, p 21). However, as discussed in Additional file 3: Appendix C, the curves would have been difficult to trace accurately in ink until after the sheet had been removed from the drum. In that case, the curves were fully inked no earlier than the stated removal date, December 1 (Additional file 3: Figure C9a).

We traced and rearranged the tidal curves on the marigram scan to yield the single time series presented here as a tracing (Figs. 3a, 4a, and Additional file 3: C2) and as points digitized from that tracing (Fig. 5, black curves; Additional file 4: Table S1). The tides of largest amplitude (spring tides) are centered near November 20, and tides of lesser range (neap tides) coincide with the tsunami of November 28 and 29. The maximum gauged water level during the tsunami is $2.81 \mathrm{~m}$ near 0750 IST on November 28 . This maximum exceeds mean high water springs (2.5 m in Hydrographic Department 1944, p 293) but falls short of the highest spring tides measured 1 week before (3.26 $\mathrm{m}$ close to the midnight of November 21-22; Fig. 5a), and it is about $1 \mathrm{~m}$ below the maximum water level implied by newspaper reports cited above.

\section{Gaps in the tidal curves}

The marigram contains notable gaps. The longest, spanning $9 \mathrm{~h}$ and $14 \mathrm{~h}$, occur on November 20 and 22-23, respectively. Three short gaps interrupt the purple inked 
Tsunami on November 28 and 29

a

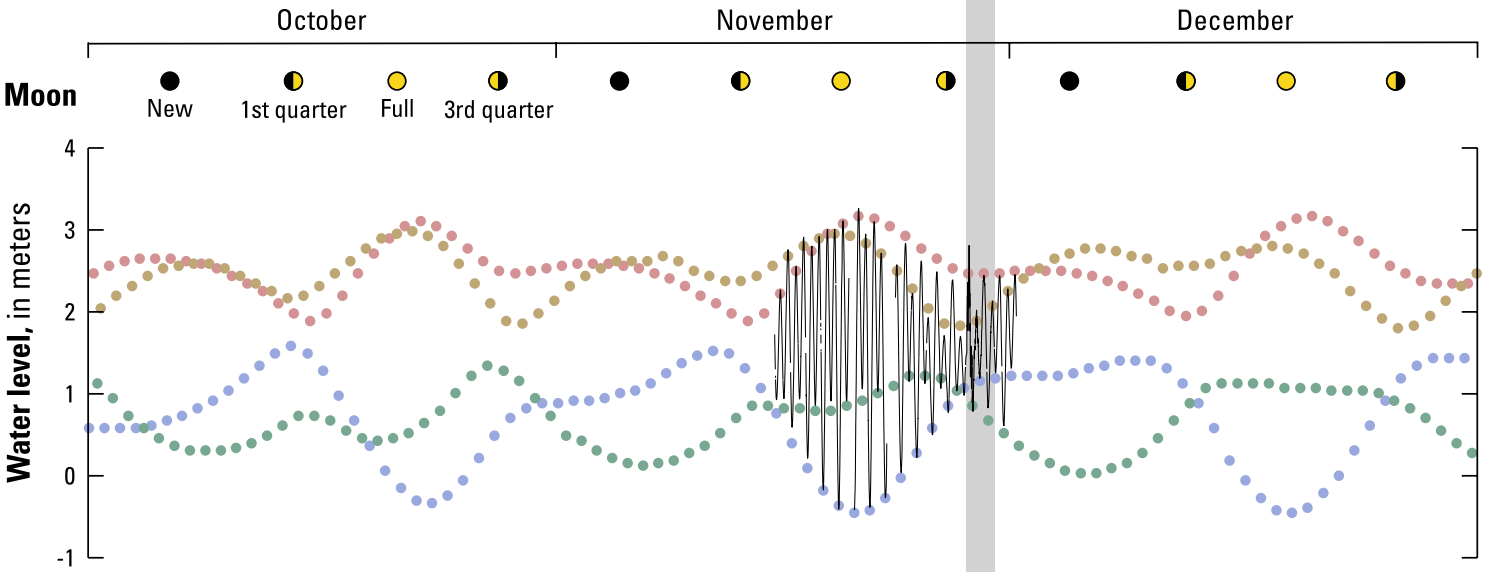

b

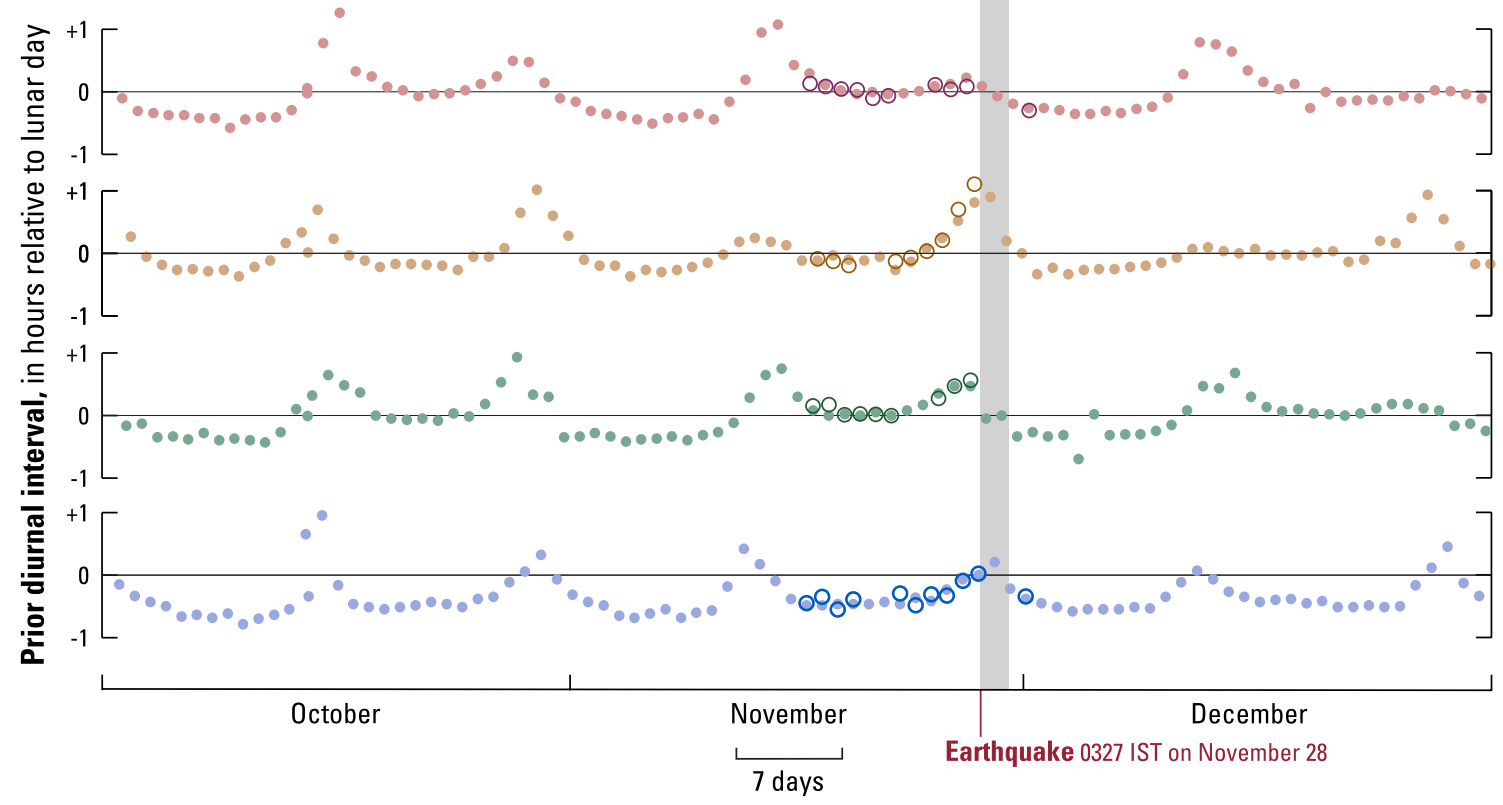

Month in 1945, India Standard Time (IST)

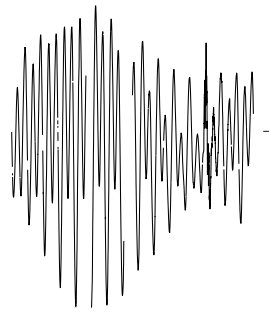

\section{EXPLANATION}

Water levels (plotted in a)

Traced marigram - Includes gaps from outages of tide gauge and from tears at edges of marigram paper

Predicted time and height of high water or low water-From Admiralty tide tables. Color denotes tides that are close to one lunar day ( $24 \mathrm{hr} 50 \mathrm{~min})$ apart, in the sets called $S_{0}(\bullet), S_{1}(\bullet), S_{2}(\bullet)$, and $S_{3}(\bullet)$ in Appendix $A$

Time interval between tides (plotted in $\mathbf{b}$ )-Time unit is difference, in hours, from one mean lunar day. Color denotes tidal set in a

.... Time interval between predicted tides-Predictions in Admiralty tide tables

○००० Time interval between fitted tides-Time evaluated at extreme height along quadratic curve fit by least squares to crest (high water) or trough (low water) in digitized, traced marigram. Not shown where marigram is interrupted by gaps on November 20 and 23, and where water levels were perturbed by the tsunami on November 28 and 29 (gray band) 
curve for November 28: for 5 min between 0208 IST and 0213 IST, as a rising tide begins to decelerate toward an eventual standstill at 0330-0400 IST (Additional file 3: Figure C3b); for 20-25 min between 0806 IST and 0830 IST, during wild fluctuations from the tsunami; and almost instantaneously at 0910 IST, at a $15-\mathrm{cm}$ jump in water level (Fig. 4a and Additional file 3: C2b).

The only gap clearly explained on the sheet is the one labeled directly as having begun at 0806 IST and ended at 0830 IST. A note at lower right on the sheet (Additional file 1: Figure S1), signed by the port's chief engineer, D.B. Brow, describes a mechanical problem: "Between 0810 and 0830 on the 28th Nov'45 the recorder did not register owing to a tidal wave having caused the copper belt to slip off the wheel" (Additional file 3: Figure C8c). This copper belt was probably the one from which the float was suspended in the stilling well. The "wheel" in Brow's note likely refers to the one that the copper belt ordinarily turned. The wheel would then rotate gears that controlled a chain connected to the pencil that drew the marigram on a rotating drum (gauge design, above). The "belt off wheel" problem may apply to the step at 0910 IST as well, which coincides, like the gap of 0806-0830 IST, with rapid changes in water level (Fig. 4a).

The gap of $0806-0830$ IST approximately coincides with the maximum water levels in newspaper accounts cited above. These maxima are attained around 8 a.m. in two accounts (Daily Gazette, Sind Observer) and at 8:15 in another (Times of India). The reported times, however, are difficult to relate to those measured more precisely at the Karachi tide station (Fig. 2a). Available evidence does not show whether the gauge recorded the maximum water level attained there on November 28.

\section{Early anomaly on November 28}

The 5-minute gap between 0208 IST and 0213 IST precedes abrupt changes in water level but appears early in a greater anomaly. Between 0030 IST and 0145 IST, the steep limb of a rising tide is initially headed toward the November 28 higher high water. Next, the rise steadily diminishes to a stillstand at $0330-0400$ IST. An anomalously rapid rise in water level follows, beginning with a 15-cm jump at 0415 IST and continuing until 0500 IST (Figs. 4a, 5b).

This early anomaly need not represent water-level changes in Karachi Harbour. It was discounted as an artifact of the gauge by Neetu et al. (2011), who accordingly excluded it from their nine-hour tracing of the Karachi marigram, and from their plot of residual water levels after detiding (Fig. 5c) - a precedent followed by Heidarzadeh and Satake (2015), their Fig. 2b. According to Neetu et al. (2011, p 1612), "The tide gauge at Karachi had malfunctioned before the tsunami struck there. The officer in charge of the tide gauge had marked on the chart that the gauge was out of order. Fortunately, the gauge had resumed recording just before the arrival of the initial wave."

Additional file 3: Appendix C considers several possible explanations for the early anomaly. The leading candidate is temporary obstruction of the communication hole in the stilling well-a prior problem with the Karachi tide station (Eccles 1901b, p 9, Survey of India 1924, p 52). Found unlikely is a clerical explanation in which an anomaly on November 29 gets mistakenly assigned to November 28 . As for natural causes of a genuine anomaly, Additional file 3: Appendix $C$ presents archival evidence against unusual weather and offers suggestions for tsunami modeling of hypothetical slope failures and slow earthquakes.

\section{High water and low water predictions in official tide tables}

Karachi tide tables for 1945 were published by the British Admiralty (Hydrographic Department 1944, pp 104-106). Identical predictions, probably provided by the Admiralty, were published by the US Coast and Geodetic Survey (1944, pp 292-295). The tables give heights and times of high water and low water. We obtained the Admiralty tables from the main library of the National Oceanic and Atmospheric Administration. The tide-table predictions most important to this paper are presented in Fig. 4b, which uses time intervals derived from them. The predicted time intervals resemble the gauged intervals plotted with open circles in Fig. 3b. We obtained these gauged intervals after fitting quadratic curves to high waters and low waters, as described below and in Additional file 2: Appendix A.

The tide tables relate predictions to the height datum of the area's nautical chart of largest scale. For Karachi, this is the datum to which soundings were reduced on Admiralty chart 40 (Hasan et al. 2018). The Karachi tide gauge used this same datum in 1937-1948 (Permanent Service for Mean Sea Level 2016).

\section{Tide tables and harmonic constituents}

The Admiralty tide tables for November 15 to December 1, 1945 predict times and heights of high waters and low waters that approximate those displayed on the marigram from the Karachi tidal observatory, outside the tsunami window of November 28 and 29. For high waters and low waters fitted by quadratic curves, the maximum differences from the tide-table predictions are $25 \mathrm{~min}$ and $20 \mathrm{~cm}$ (data in Additional file 4: Table S3). For low waters and high waters selected by eye from the marigram scan, the maximum difference from tide tables is also $20 \mathrm{~cm}$ in height but is greater in time, nearly $35 \mathrm{~min}$.

This overall agreement between prediction and observation attests to the use, in the Admiralty tide tables, of 
harmonic constituents derived from the long history of tide gauging at the 1945 location of the tidal observatory. Tidal observations during the 53 years of from 1868 to 1920 provided the basis for the Admiralty's 1945 tide tables for Karachi (Hydrographic Department 1944, p 293) and for 35 harmonic constituents published by the International Hydrographic Bureau (1966, sheet 123).

\section{Trends in high waters and low waters}

The detiding method makes use of dependably gradual trends in the times and heights of tides that follow one another by one mean lunar day on average. One mean lunar day is 1.0351 solar days, or $24 \mathrm{~h} 50 \mathrm{~min}$ (Pugh and Woodworth 2014, p 49). Two sets of high tides and two sets of low tides repeat at this lunar-day frequency because Karachi tides are predominantly semidiurnal. The four lunar-day sets are coded by color in Figs. 3 and 4 .

The four lunar-day sets meander through spring-neap cycles in the Admiralty predictions for October through December, 1945 (Fig. 3a). Outside November 28 and 29, observations (quadratic fitted tides) between November 15 and December 1 follow or parallel these trends (Fig. 4, open circles).

Within each lunar-day set, the height change from one tide to the next rarely exceeds $30 \mathrm{~cm}$ and is commonly less than $20 \mathrm{~cm}$ (Fig. 3). This modest height change, across one lunar day, yields gentle slopes on curves that pass through the successive tides (Fig. 4)-a property used below to limit uncertainty in height estimates for high waters and low waters that we compute.

The predicted intervals between successive tides within a lunar-day set deviate by as much as $1 \mathrm{~h}$ from one mean lunar day (Fig. 3b). The largest deviations coincide with neap tides, including those of November 28 and 29. This erratic behavior may add uncertainty to the high water and low water times that are computed in steps 1 through 3 , below.

The marigram gives times and heights consistent with these predicted intervals. For times derived by fitting quadratic curves to crests and troughs in the digitized marigram tracing, the fitted intervals differ from the predicted intervals by $20 \mathrm{~min}$ at most, and most of the differences are under $10 \mathrm{~min}$ (Fig. 3b). This agreement, obtained outside the time of the tsunami, strengthens the basis for applying the predicted intervals to the computation of high water and low water times during the tsunami, on November 28 and 29.

\section{Computed Karachi tides for the time of the tsunami}

The detiding relies on a reference tidal curve we call the Accepted Tide. Its derivation is diagrammed in Fig. 4, described mathematically in Additional file 2: Appendix $\mathrm{A}$, and compared with other detiding methods in Additional file 2: Appendix B. The Accepted Tide is intended to approximate a purely tidal curve for November 15 to December 1, 1945. It is plotted in light blue in Fig. 5 , where it is also differenced from a digitized version of the traced marigram. It is presented in tabular form, at 1-min intervals, in Additional file 4: Table S2.

The Accepted Tide is anchored in 64 control points presented in Additional file 4: Table S3. Each represents a different high water or low water. Most are derived from two kinds of times and heights of the high water or low water-predicted values from the Admiralty tide tables, and observed values from the marigram. Control points on November 28 and 29, during the tsunami, have a third set of values discussed below. In Additional file 2: Appendices A, B, the control points are called extrema, and each extremum is assigned a number that is listed in Additional file 4: Table S3 and plotted in Additional file 2: Figure B1.

Outside the time of the tsunami, values for most of the control points used in the Accepted Tide were obtained from the quadratic curves that were fitted to high water crests and low water troughs in the digitized tracing of the marigram. Some of these crests and troughs are broad, undulatory, and (or) asymmetrical. Accordingly, each tidal crest or trough was fitted with a least-squares quadratic curve that provides a single, objectively estimated time and height for each gauged high water or low water. To check these quadratic fitted times and heights, we compared them with a subjective, visual selection of the central time point of maximum or minimum height. This manual approach offers the advantage of direct measurement to the nearest lithographed grid lines for time and height. The two methods gave results that differ in time by as much as $20 \mathrm{~min}$, but in height by no more than $3 \mathrm{~cm}$. Accordingly, only the quadratic fitted times and heights are used in the detiding below.

The lunar-day trends in predicted tides facilitate computation of the Accepted Tide on November 28 and 29. The trends provide a framework for refining tide-table predictions of high waters and low waters on those days, and for doing so without influence from the tsunami. To avoid influence from the tsunami, the Accepted Tide for November 28 and 29 is based on control points that were obtained indirectly by the method that is described below. This method is diagrammed in Fig. 4 and is described more precisely in Additional file 2: Appendix A.

To complete the Accepted Tide, cubic polynomials were fit piecewise, as a spline, to the control points from successive high waters and low waters between November 15 and December 1 (last columns of Additional file 4: Table S3). The resulting curve is evaluated at 1-min intervals in Additional file 4: Table S2. The Accepted Tide in Additional file 4: Table S1 and Fig. 5 is evaluated only at the times that were digitized on the marigram tracing. 


\section{(See figure on next page.)}

Fig. 4 Graphical depiction of method for computing times and heights of high waters and low waters on November 28 and 29, by means of interpolation of predicted and observed heights outside that time window. a Overview of tide table predictions (color) and gauged water levels (black curve and circles) November 26 to December 1, along with high waters and low waters computed in $\mathbf{b}$. Each dotted line is a cubic spline fit to the four lunar-day sets of high waters and low waters, and the associated tide table predictions are keyed by color to Fig. 3. b Computation of times and heights for November 28 and 29 (bold) for each of the four lunar-day sets. The splines in a (dotted color lines) are reproduced separately in (b) for each set. Ratios of predicted intervals between lunar-day tides (upper bracket with each set) are projected onto a slightly adjusted timeline controlled at its ends by high water and low water times gauged November 27 and November 30, outside the time of the tsunami (lower bracket). Evaluating the splines at the computed times gives the computed heights

\section{Computations diagrammed}

The procedures below and in Additional file 2: Appendix A can be visualized with reference to Fig. 4. Figure 4a compares three kinds of control points-predicted, fitted, and computed-with a tracing of the marigram between November 26 and December 1 (black curve). The lunarday sets of Fig. 3 are adapted here as cubic polynomials (dotted, color curves). These dotted curves have been fitted piecewise to time and height values that were derived by fitting quadratic curves to crests and troughs of high waters and low waters, respectively, between November 15 to December 1, but excluding November 28 and 29.

The points plotted as open squares in Fig. 4 were obtained with computational steps, below, that can be tracked along the four lunar-day curves in Fig. 4b. Reproduced there is each of the four lunar-day cubic polynomials in Fig. 4a-color-coded purple, brown, green, and blue. Also reproduced for each color, from Fig. 4a, are the control points derived from fitting of quadratic curves to the digitized, traced marigram (open circles; "fitted" points in Additional file 4: Table S3). Reproduced as well are predictions from tide tables (solid circles) and computed times and heights (open squares).

These various times and heights-predicted, fitted, and computed-are arrayed along two brackets for each of the four lunar-day curves. The numbers beside these brackets are labeled for the first example only (purple). Beside the upper bracket, the times from tide tables correspond to time ratios between fitted control points. The bracket below each dotted curve retains these ratios but has been shifted to align the bracket ends to the fitted points outside the tsunami window. Times inside the tsunami window are computed by applying the predicted ratios to this shifted bracket. Those times, evaluated on the polynomial, give the computed heights which, like the computed times, are in bold font.

\section{Computational steps}

1. From the Admiralty tide tables, time intervals are obtained between successive predicted tides in each lunar-day set. The intervals are determined with tides both outside the tsunami window (November 27 and 30 ) and within the tsunami window (November 28 and 29). The predicted lunar-day intervals between these extremes (Fig. 3b) are then converted into ratios that give the relative position of a predicted tide in the shortest lunar-day series that spans November 28 and 29. Each such series is represented in Fig. 4b by paired, facing brackets, one pair per lunar-day set. The upper bracket shows times and ratios from tide tables. Three of these predicted brackets (along the purple, brown, and green curves) span three intervals each, and the predicted ratios along them are close to $1 / 3$ and $2 / 3$. The other predicted bracket (along the blue curve) spans two intervals, with a predicted ratio close to $1 / 2$.

2. The paired bracket, placed below the curve, is shifted slightly in time. It retains the time ratios from tide tables but uses endpoints at fitted quadratic times on November 27 (before any tsunami) and on November 30 (tsunami mostly dissipated; Fig. 5a).

3. The predicted time ratios in each upper bracket, applied to fitted quadratic times on the paired lower bracket, yield computed times for high waters and low waters on November 28 and 29.

4. Water levels are then obtained by evaluating the gently sloping cubic spline (dotted line, color) at each computed time. This spline is controlled outside the time of the tsunami by fitted quadratic values, derived from the digitized marigram tracing for November 27 and 30, of high waters or low waters along a lunar-day time series.

\section{Assumptions and uncertainties in the interpolations}

It is assumed that the time-interval ratios derived from tide tables apply to the tidal component of water-level changes during the tsunami window of November 28 and 29 . This assumption is supported by the overall agreement, between predicted and observed (quadratic fitted), in the intervals between successive lunar-day tides (Fig. 3b).

How well do the four steps above reproduce times and heights of high waters and low waters observed outside the time of the tsunami? We found no time differences larger than $10 \mathrm{~min}$ and no height differences greater than $2 \mathrm{~cm}$. Larger time errors may be possible in the tsunami 


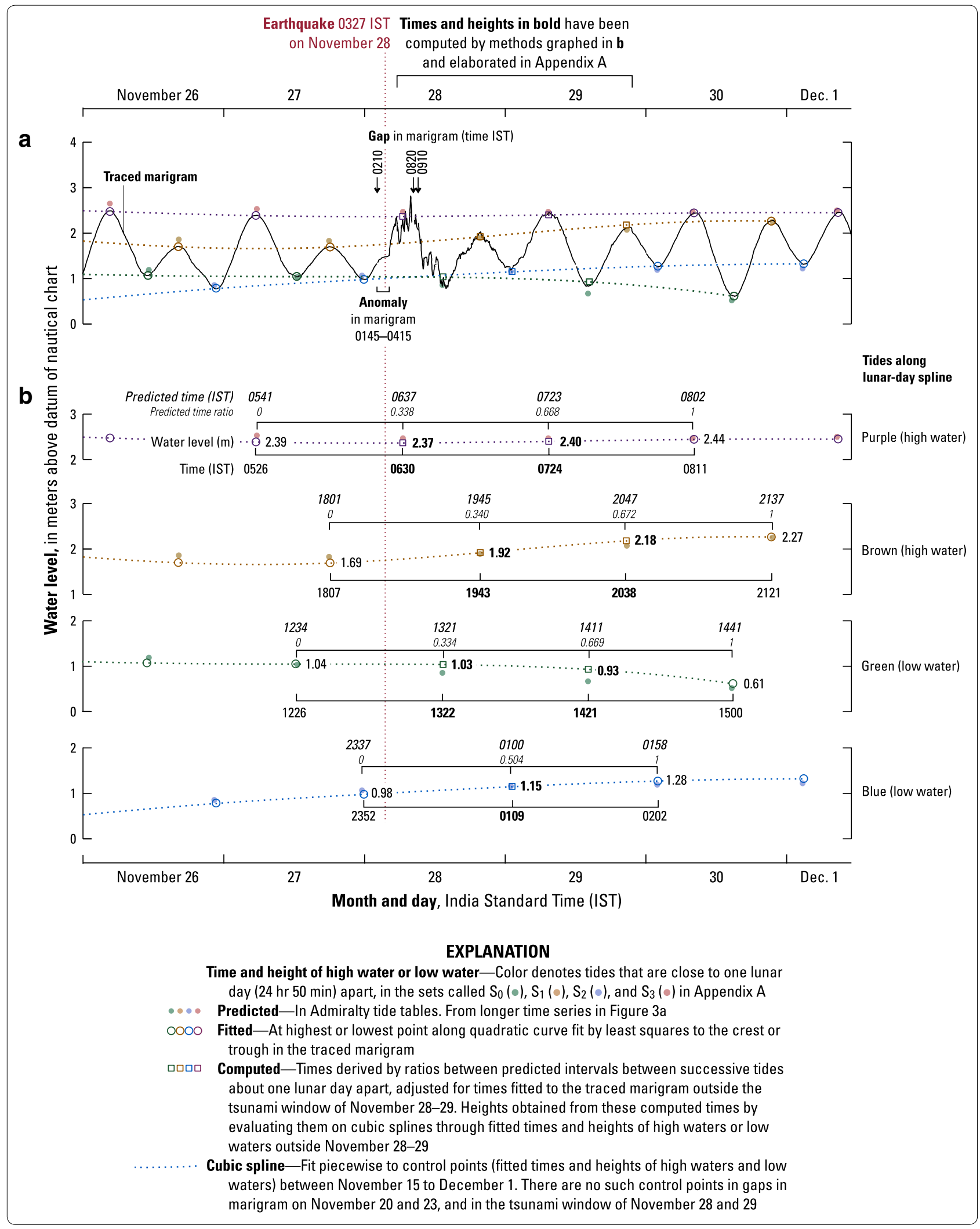




\section{(See figure on next page.)}

Fig. 5 Detiding of the Karachi marigram. a November 15 to December 1, 1945. Digitized version of traced marigram (black) is superimposed on tidal curve (light blue) approximated by piecewise fit of cubic polynomials to high waters and low waters — control points that were computed as in Fig. 5 for the days of the tsunami (November 28 and 29) and for two prior outages (November 20 and 23), and were fitted to the traced marigram outside those time windows. Graph of residual shows difference between these black and light blue curves. b As in a, but for November 27-29. c Previously detided curve for part of November 28 from Neetu et al. (2011, p 1613)

window because it coincides with neap tides, when time intervals between successive lunar-day tides are most erratic (Fig. 3b). But errors of a few tens of minutes in time probably add little error in water level, because of the gentle slopes of the cubic spline on which the heights are evaluated (Fig. 4b).

A gently sloping cubic spline limits likely error in the height computed for the most important of the tides during the tsunami. This is the higher of the two high waters on November 28-the tide mentioned by Pendse $(1946,1948)$ as having shortly preceded the peak water levels that were observed in the Karachi area during the tsunami. The height of this tide is evaluated along the dotted purple curve that passes through fitted quadratic times and heights of the higher high waters on November 27 and 30 (Fig. 4b). This purple curve has a gentle slope because it passes through water levels of $2.39 \mathrm{~m}$ on November 27 and $2.44 \mathrm{~m}$ on November 30 . The higher high water for November 28 , computed as $2.37 \mathrm{~m}$, cannot stray far from this narrow range of heights.

\section{Cubic approximation to a complete tidal curve}

The fitted quadratic control points outside the tsunami window, and the computed high waters and low waters within it, provide the framework for the Accepted Tide, as an approximation to a complete tidal curve. To complete the Accepted Tide, a cubic polynomial was fitted to each successive pair of control points, with the constraint of having zero slope at these points. The polynomials were then combined, as a piecewise polynomial, to approximate a complete Karachi tidal curve for November 15 to December 1, 1945. We then used the Accepted Tide to detide the digitized tracing of the marigram (Fig. 5a, b; Additional file 4: Tables S1 and S2).

The most important part of the Accepted Tide includes the time when the tsunami arrived and when it produced maximum water levels. For this interval, early on November 28, the Accepted Tide is anchored in two control points. The first is the last of the tides gauged before the tsunami, for which we use the fitted quadratic time and height of the low water near the midnight of November 27-28. The second is the securely computed higher high water, just discussed, that was predicted for 0637 IST on November 28. It is this part of the Accepted Tide that includes the time of the anomalously slow rise at 01450415 IST (Additional file 3: Appendix C), and which continues into the time of the maximum water levels around 0800 IST.

\section{Detided water levels on November 28 and 29}

The full marigram detided in Fig. 5a shows many residual fluctuations outside the tsunami window of November 28-29. Few deviate from zero by more than $10 \mathrm{~cm}$ and none by more than $20 \mathrm{~cm}$. Their likely causes include real changes in water level, the simplicity of the cubic piecewise approximation in the Accepted Tide, and errors inherent in the recording and digitizing of the marigram. The anomalies include, on November 19, a small version of the early anomaly of November 28 (Additional file 3: Figures $\mathrm{C} 2$ and $\mathrm{C} 3$ ).

Anomalies on November 28-29 stand out from this background (Fig. 5b). With respect to ambient tide, apparent water levels early on November 28 decline about $0.5 \mathrm{~m}$ between 0145 and 0415, and they fall again, but less gradually, near 0600 and 1000 . The greatest of the gauged tsunami heights, close to 0800 , slightly exceeds $0.5 \mathrm{~m}$ above ambient tide. As noted above, a greater height may have been attained while the copper belt was off the wheel, soon after 0800 (Additional file 3: Figures C2b and C8c). Continued fluctuations through November 29, though of low amplitude, contrast with the smooth residual curve on November 27, before the tsunami.

The new residual differs from its predecessors by spanning more than 9 hours, by displaying the early anomaly of 0145-0500 IST, and by not imposing symmetry between major crests and troughs (Fig. 5). Asymmetry in the newly detided marigram depresses both a crest at 0500 IST and a trough at 0600 IST on November 28, with respect to detiding by Neetu et al. (2011). Similar differences would be apparent in a comparison with the detided marigram in Heidarzadeh and Satake (2015, p 624), because of its resemblance to Fig. $5 \mathrm{c}$.

The new residual is plotted in Fig. 5 as a series of points that ensure display of data gaps. The potentially important data gap soon after 0800 IST is neglected if the residual is plotted as a continuous line, as in Additional file 3: Figure C4 and the Karachi graphs of Heidarzadeh and Satake (2015). 


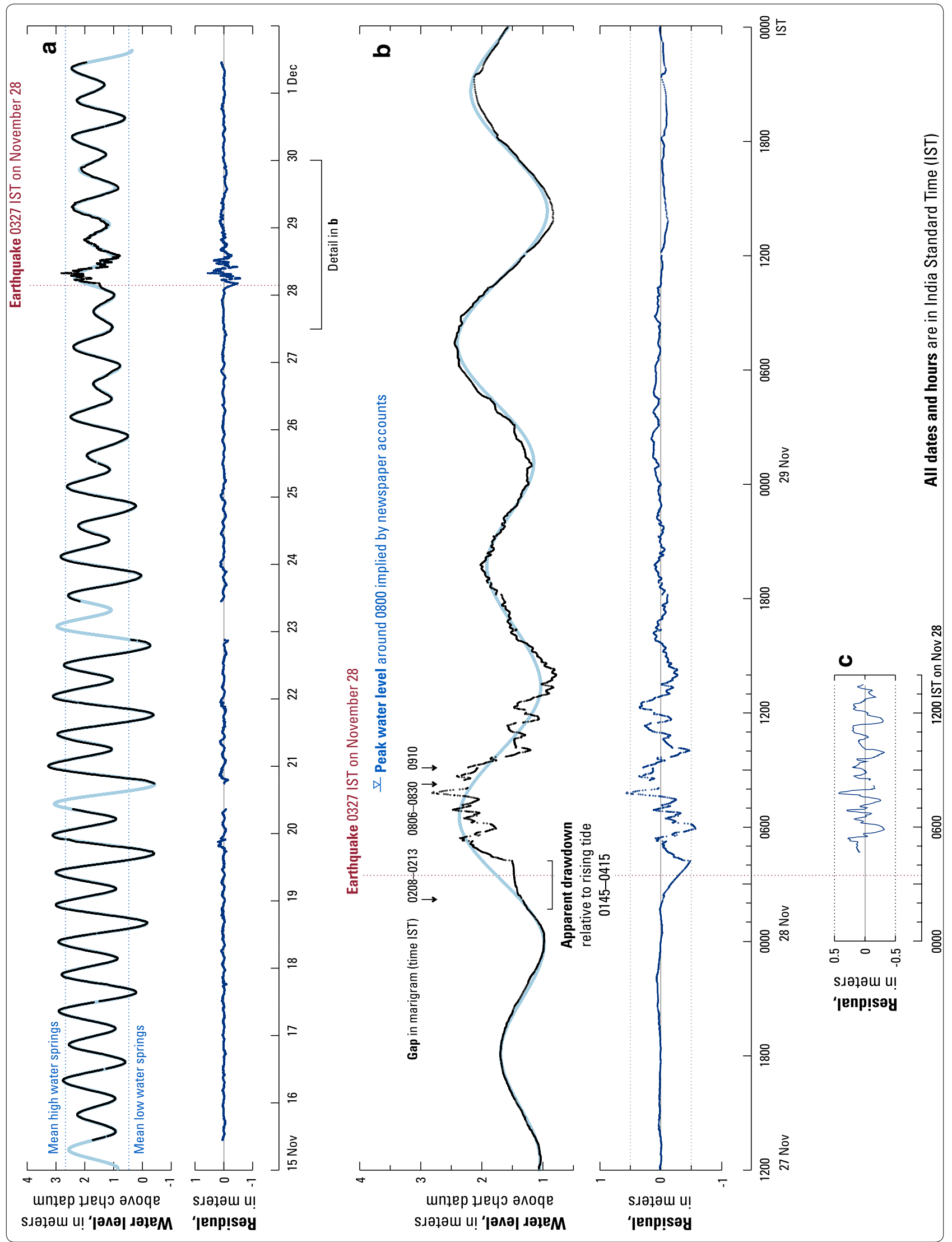




\section{Implications for tsunami risk assessment Detiding methods}

The Karachi marigram could have been detided by assuming that a tsunami would fluctuate more or less symmetrically, at periods of an hour or less, about a tidal curve. This assumption is built into the so-called Alternative Tide presented in Additional file 2: Appendix B. The Alternative Tide passes through the apparent slowing of the rising tide at 0145-0415 IST, and through the anomalously rapid water-level rise of 0415-0500 IST. Subtracted from the digitized marigram, the Alternative Tide still shows an apparent drawdown, but gives its amplitude as $-0.32 \mathrm{~m}$, versus $-0.48 \mathrm{~m}$ with the Accepted Tide (Additional file 2: Figure B2c). In addition, because it was fit through the apparent drawdown, the Alternative Tide yields an initial rise in the detided water level, and it delays the onset of negative values by an hour with respect to the Accepted Tide.

Fitting a polynomial through fluctuations during the tsunami has smaller effects on tsunami amplitudes later in the morning of November 28. These effects result from a half-hour delay, in the Alternative Tide, of the first high tide after the earthquake. This is the higher high water, at 0637 IST in the Admiralty tide tables, that Pendse $(1946,1948)$ used to estimate that the tsunami, around 0800 IST, crested nearly $1.5 \mathrm{~m}$ above ambient tide. The Accepted Tide hastening this high water slightly to 0631 IST. It is delayed until about 0705 IST in the Alternative Tide, because of curve-fitting to the positive waves between 0500 IST and 0900 IST. However, for the maximum gauged water level at 0747 IST, the detided tsunami amplitudes are similar: $2.29 \mathrm{~m}$ with the Alternative Tide, and $2.37 \mathrm{~m}$ with the Accepted Tide.

Fitting a polynomial through fluctuations on November 29 eliminates an overall positive anomaly that, with the Accepted Tide, spans most of the first half of that day, during a rising tide (Fig. $5 \mathrm{~b}$ and Additional file 3: C4b). The amplitude of this broad anomaly is $0.1-0.2 \mathrm{~m}$, small enough to ascribe to errors in the preceding low water and succeeding high water. Alternatively, the anomaly is genuine and may be part of the tsunami, as posited in Additional file 3: Appendix C.

Additional comparisons among detiding methods are offered in Additional file 2: Appendix B. The methods considered include using 35 harmonic constituents derived from tidal observations at Karachi between 1868 and 1920 (International Hydrographic Bureau 1966, sheet 123).

\section{Tsunami sources}

The findings in this paper may complicate the modeling of sources for the 1945 Makran tsunami, in at least three respects:
1. An early anomaly could be evaluated as evidence for a precursory slope failure or slow earthquake. First, however, additional archives could be sought in hopes of clarifying the cause and duration of the labeled outage at 0210 IST.

2. The detided marigram is deficient in positive waves through the first $4 \mathrm{~h}$ after the earthquake. To produce this result, positive waves before 0730 IST need to be supermimposed on a persistent drawdown. Such a drawdown could go undetected by detiding that imposes symmetry.

3. The marigram may understate maximum tsunami height. This possibility arises not just from the data gap soon after 0800 IST but also from the stilling well's vulnerability to blockage. As a partial workaround, tsunami simulations could extend to seawalls that the tsunami reportedly overtopped. The physiographic grid could include a digital elevation model that uses bathymetry and shorelines from the middle of the 20th century (Hasan et al. 2018).

\section{Additional files}

Additional file 1: Figure S1. Scan of Karachi marigram for November 15 to December 1, 1945.

Additional file 2: Appendix A. Mathematical description of the detiding method. Appendix B. Comparison among detiding results.

Additional file 3: Appendix C. Potential explanations for an early anomaly in the Karachi tide-gauge record for November 28, 1945.

Additional file 4: Table S1. Times and heights from a digitized tracing of the Karachi marigram for November 15 to December 1, 1945, compared with the tidal curve accepted for use in this paper. The difference is the residual that is plotted, along with the digitized tracing and the Accepted Tide, in parts a and b of Fig. 5. Height datum assumed to be that of Admiralty chart 40. (Caution to Apple users: In the Microsoft date-andtime convention of this spreadsheet, and in Tables S2 and S3 as well, dates formatted a single series of numbers start 4 years earlier, on January 1 , 1900, than in the 1904 date system used in Excel for Macintosh.). Table S2. Accepted tide for all times between November 15 and December 1, evaluated at intervals of $1 \mathrm{~min}$. Table S3. Five representations of heights and times and heights of high waters and low waters between November 15 and December 1, 1945: (a) predictions in Admiralty tide tables for Karachi (Hydrographic Department 1944); (b) manual measurements on the Karachi marigram; (c) quadratic fits to a digitized tracing of the marigram; (d) computations made where the marigram lacks tidal measurements (control points 21, 22, 31, and 32), or where the tsunami perturbs the marigram curve (control points 51-57); and (e) times and heights that control the piecewise cubic spline of the Accepted Tide in Table S2. The control points for this spline: 0,1 , and 64 from (a); 21, 22, 31, 32, and 51-57 from (d); and all others from (c).

Authors' contributions

LMA devised the detiding method, generated the fitted and computed control points, calculated the Accepted Tide and the residual, and prepared Additional file 2: Appendices A and B. BFA traced the marigram, drafted the text and Figs. 1, 2, 3, 4, 5, and prepared Additional file 3: Appendix C. HH digitized the tracing and considered the gauge response to rapid changes in water level and a constricted orifice. All authors read and approved the final manuscript. 


\section{Author details}

${ }^{1}$ Department of Applied Mathematics, University of Washington, Seattle, WA USA. ${ }^{2}$ U.S. Geological Survey at University of Washington, Seattle, WA, USA.

${ }^{3}$ Department of Civil Engineering, NED University of Engineering and Technology, Karachi, Pakistan.

\section{Acknowledgements}

The marigram scan was provided by Satheeesh C. Shenoi of INCOIS, with assistance from Srinivasu Kumar Tummala of UNESCO-IOC, Laura Kong of the International Tsunami Information Centre, and Ajay Kumar Bandela of INCOIS. Lindsey M. Wright of the National Oceanic and Atmospheric Administration alerted us to evidence that the marigram had been overwritten. NOAA librarian Brian Voss obtained archival tide tables and weather data. Lynn R. Sykes of Lamont-Doherty Earth Observatory provided guidance on earthquake catalogs. Clues to the Karachi tide gauge as of 1945 were provided by Philip Woodworth of the National Oceanography Centre, Liverpool and by Peter Hogarth of Kongsberg Maritime, Great Yarmouth, UK. Thoughtful reviews of a previous draft were provided by Jian Lin of Woods Hole Oceanographic Institution, Nina Kukowski of Friedrich-Schiller-Universität Jena, and Finn Løvholt of the Norwegian Geotechnical Institute. The comments of two journal referees prompted revisions that include the addition of Additional file 3: Appendix C.

\section{Competing interests}

The authors declare that they have no competing interests.

\section{Availability of data and materials}

Supporting data are provided in Additional files 1, 2, 3, 4.

\section{Funding}

This work was initiated under a UNESCO project supported by the United Nations Economic and Social Commission for Asia and the Pacific. Additional support was provided by the US Agency for International Development through its Office of Foreign Disaster Assistance and the US Geological Survey.

\section{Publisher's Note}

Springer Nature remains neutral with regard to jurisdictional claims in published maps and institutional affiliations.

Received: 2 March 2018 Accepted: 21 August 2018

Published online: 26 September 2018

\section{References}

Agent to the Governor General in Baluchistan (1948) Baluchistan Agency administration report for 1945-1946

Ambraseys NN, Melville CP (1982) A history of Persian earthquakes. Cambridge University Press, Cambridge, p 219

Barns M (1940) The Indian press; a history of the growth of public opinion in India. G. Allen \& Unwin Ltd, London, p 491

Byrne DE, Sykes LR, Davis DM (1992) Great thrust earthquakes and aseismic slip along the plate boundary of the Makran subduction zone. J Geophys Res 97:449-478

Eccles J (1901) Details of the tidal observations taken during the period from 1873 to 1892 and a description of the methods of reduction; Part I. Description of the instrumental equipment and of the operations generally with details of the system of observing and of reducing the observations, vol XVI. Account of the Operations of the Great Trigonometrical Survey of India, Dehra Dun, 383 pp

Eccles J (1901) Details of the tidal observations taken during the period from 1873 to 1892 and a description of the methods of reduction; Part II. History and description of the observatories, results of the observations, and values of the tidal constants, up to 1892, vol XVI. Account of the Operations of the Great Trigonometrical Survey of India, Dehra Dun, 152 pp

Hasan H, Lodhi HA, LeVeque RJ, Lodhi SH, Ahmed S (2017) Assessing tsunami risk to Karachi Port through simulation of currents that were reportedly produced there by the 1945 Makran tsunami. In: Proceedings of the 16th world conference on earthquake engineering, Santiago, Chile, January 8-13, 2017
Hasan H, Atwater BF, Ahmed S (2018) A digital elevation model for simulating the 1945 Makran tsunami in Karachi Harbour. Geosci Lett. https://doi. org/10.1186/s40562-018-0117-8

Heidarzadeh M, Satake K (2015) New insights into the source of the Makran tsunami of 27 November 1945 from tsunami waveforms and coastal deformation data. Pure Appl Geophys 172:621-640. https://doi. org/10.1007/s00024-014-0948-y

Heidarzadeh M, Satake K (2017) A combined earthquake-landslide source model for the tsunami from the 27 November $1945 M_{w} 8.1$ Makran earthquake. Bull Seis Soc Am 107:1033-1040. https://doi.org/10.1785/01201 60196

Heidarzadeh M, Pirooz MD, Zaker NH, Yalciner AC, Mokhtari M, Esmaeily A (2008) Historical tsunami in the Makran Subduction Zone off the southern coasts of Iran and Pakistan and results of numerical modeling. Ocean Eng 35:774-786. https://doi.org/10.1016/j.oceaneng.2008.01.017

Hoffmann G, Rupprechter M, Al Balushi N, Grützner C, Reicherter K (2013) The impact of the 1945 Makran tsunami along the coastlines of the Arabian Sea (northern Indian Ocean) — a review. Zeitschrift für Geomorphologie Suppl Issue 57(supplement 4):257-277. https://doi. org/10.1127/0372-8854/2013/S-00134

Hogarth P (2014) Preliminary analysis of acceleration of sea level rise through the twentieth century using extended tide gauge data sets. J Geophys Res 119:7645-7659. https://doi.org/10.1002/2014jc009976

Hydrographic Department (1944) The Admiralty tide tables; Part I. Tidal predictions for the year 1945; Section B. Foreign waters. Admiralty, City of Westminster, $303 \mathrm{pp}$

International Hydrographic Bureau (1966) Tides: harmonic constants. Special Publication No. 26

Kakar DM, Naeem G, Usman A, Mengal A, Naderi Beni A, Afarin M, Ghaffari $\mathrm{H}_{\text {, }}$ Fritz HM, Pahlevan F, Okal EA, Hamzeh MA, Ghasemzadeh J, Al-Balushi NS, Hoffmann G, Roepert A, Seshachalam S, Andrade V (2015) Remembering the 1945 Makran tsunami; interviews with survivors beside the Arabian Sea. UNESCO-IOC Brochure 2015-1, 79 pp. http://www.ioc-tsunami.org/ index.php?option=com_content\&view $=$ article\&id=293:1945-makra $\mathrm{n}$-tsunami\&catid $=20 \&$ lang $=$ en\&ltemid $=68$

Neetu S, Suresh I, Shankar R, Nagarajan B, Sharma R, Shenoi SSC, Unnikrishnan AS, Sundar D (2011) Trapped waves of the 27 November 1945 Makran tsunami: observations and numerical modeling. Nat Hazards 59:1609_ 1618. https://doi.org/10.1007/s11069-011-9854-0

Pendse CG (1946) A short note on the Mekran earthquake of 28th November 1945. J Sci Ind Res 5:106-108

Pendse CG (1948) Mekran earthquake of the 28th November 1945. Sci Notes 10:141-145

Permanent Service for Mean Sea Level (2016) Karachi (station 204). National Oceanography Centre, Liverpool. http://www.psmsl.org/data/obtaining/ stations/204.php. Accessed Aug 102016

Pugh D, Woodworth P (2014) Sea-level science: understanding tides, surges, tsunamis and mean sea-level changes. Cambridge University Press, Cambridge, p 395

Rajendran CP, Ramanamurthy MV, Reddy NT, Rajendran K (2008) Hazard implications of the late arrival of the 1945 Makran tsunami. Curr Sci 95:1739-1743

Rastgoftar E, Soltanpour M (2016) Study and numerical modeling of 1945 Makran tsunami due to a probable submarine landslide. Nat Hazards 83:929-945. https://doi.org/10.1007/s11069-016-2356-3

Reingold EM, Dershowitz N (2002) Calendrical tabulations, 1900-2200. Cambridge University Press, Cambridge, p 606

Sharma MSM (1954) Peeps into Pakistan. Pustak Bhandar, Patna, p 200

Survey of India (1924) Annual reports of parties and offices 1921-1922. Records of the Survey of India v. 18 (Supplementary to General Report 1921-1922), 132 pp. https://babel.hathitrust.org/cgi/pt?id=uc1.32106 020666415; view $=1$ up;seq $=11$

Survey of India (1948) Part III-geodetic work. Technical Report 1947 (Includes operations 1939-1947), 134 pp

US Coast and Geodetic Survey (1944) Tide tables Pacific Ocean and Indian Ocean for the year 1945. Serial no. 661, 405 pp, https://babel.hathitrust .org/cgi/pt?id=mdp.39015021925956;view=1 up;seq=11 